\title{
CYLD downregulation is correlated with tumor development in patients with hepatocellular carcinoma
}

\author{
HIROKI KINOSHITA $^{1}$, HIROHISA OKABE ${ }^{1}$, TORU BEPPU ${ }^{2}$, AKIRA CHIKAMOTO ${ }^{1}$, HIROMITSU HAYASHI ${ }^{1}$, \\ KATSUNORI IMAI $^{1}$, KOSUKE MIMA ${ }^{1}$, SHIGEKI NAKAGAWA ${ }^{1}$, NAOMI YOKOYAMA ${ }^{1}$, TAKATOSHI ISHIKO ${ }^{1}$, \\ SATORU SHINRIKI ${ }^{5}$, HIROFUMI JONO ${ }^{4}$, YUKIO ANDO ${ }^{3}$ and HIDEO BABA ${ }^{1}$ \\ ${ }^{1}$ Department of Gastroenterological Surgery, Graduate School of Medical Sciences, Kumamoto University; \\ ${ }^{2}$ Department of Multidisciplinary Treatment for Gastroenterological Cancer, Kumamoto University Hospital; \\ ${ }^{3}$ Department of Neurology, Graduate School of Medical Sciences, Kumamoto University; \\ ${ }^{4}$ Department of Pharmacy, Kumamoto University Hospital; ${ }^{5}$ Department of Diagnostic Medicine, \\ Graduate School of Medical Sciences, Kumamoto University, Kumamoto 860-8556, Japan
}

Received August 15,2012; Accepted December 21, 2012

DOI: $10.3892 /$ mco.2013.68

\begin{abstract}
The cylindromatosis $(C Y L D)$ gene is involved in tumor progression by acting as a negative regulator of nuclear factor- $\kappa \mathrm{B}(\mathrm{NF}-\kappa \mathrm{B})$. However, the clinical significance of CYLD in patients with hepatocellular carcinoma (HCC) remains unclear. To demonstrate the clinical significance of $C Y L D$ expression, we analyzed $C Y L D$ gene expression in 124 paired $\mathrm{HCC}$ and non-tumor tissues using quantitative reverse transcription-polymerase chain reaction (qRT-PCR). CYLD gene expression was detected in the patients and the cut-off value was determined by the median value of tumor-to-non-tumor $(\mathrm{T} / \mathrm{N})$ ratio. qRT-PCR analysis showed that a low CYLD expression was associated with a high serum $\alpha$-fetoprotein (AFP) value. Patients in the low $C Y L D$ expression group exhibited poorer overall survival compared to those in the high expression group $(\mathrm{P}=0.0406)$. Protein expression of CYLD was also investigated in 70 patients with HCC using immunohistochemistry. The findings showed that CYLD protein expression in tumor tissue was associated with $C Y L D$ gene expression $(\mathrm{P}=0.031)$. The findings of the present study suggest that CYLD is clinically associated with tumor development in HCC patients.
\end{abstract}

Correspondence to: Professor Hideo Baba, Department of Gastroenterological Surgery, Graduate School of Medical Sciences, Kumamoto University, 1-1-1 Honjo, Kumamoto, Kumamoto 860-8556, Japan

E-mail: hdobaba@kumamoto-u.ac.jp

Abbreviations: AFP, $\alpha$-fetoprotein; $C Y L D$, the cylindromatosis gene; HCC, hepatocellular carcinoma; PIVKA-II, protein induced by vitamin $\mathrm{K}$ absence or antagonist-II; qRT-PCR, quantitative reverse transcription-polymerase chain reaction

Key words: cylindromatosis gene, hepatocellular carcinoma, quantitative reverse transcription-polymerase chain reaction

\section{Introduction}

Hepatocellular carcinoma (HCC) is one of the most common gastrointestinal malignancies and constitutes the leading cause of cancer-related mortality in East Asia and South Africa (1). Currently, the first-line treatment for HCC is liver transplantation or surgical resection (2). However, the overall survival rate after curative therapy is not satisfactory due to the highly chemoresistant nature of this tumor and the frequent intrahepatic recurrence. Identification of the genes responsible for the onset and progression of HCC as well as comprehension of the clinical significance of these genes are critical for the development of successful therapies.

The cylindromatosis $(C Y L D)$ gene was originally identified as a tumor suppressor, the mutation of which predisposes patients to the development of tumors of hair follicles (cylindromas) (3). It has been reported that CYLD acts as a negative regulator of the nuclear factor- $\kappa \mathrm{B}(\mathrm{NF}-\kappa \mathrm{B})$ signaling pathway by deubiquitinating NF- $\mathrm{B}$ essential modulator (NEMO), I $\mathrm{B}$ kinase (IKK)- $\gamma$, and IKK upstream regulators, including the tumor necrosis factor (TNF), receptor-associated factor 2 (TRAF2), TRAF6, TRAF7 and receptor-interacting protein 1 (RIP1) (4-10). CYLD also regulates transforming growth factor- $\beta$ (TGF- $\beta$ ) signaling via the deubiquitination of Akt in lung fibrosis (11).

Recent studies have demonstrated that CYLD deficiency may promote the development of several types of cancer in addition to skin tumors caused by mutations and loss of the heterozygosity ( $\mathrm{LOH}$ ) of $C Y L D$. LOH of chromosome $16 \mathrm{q}$, which includes the $C Y L D$ gene, has been detected in a large proportion of multiple myeloma cases and has been associated with poor overall survival (12-14). Comparative genomic hybridization $(\mathrm{CGH})$ assays have also suggested potential genetic abnormalities of $C Y L D$ (reduction in copy number) in HCC, uterine carcinoma and renal cancer (15-17). Moreover, suppressed $C Y L D$ gene expression may contribute to tumor development in colon cancer, hepatocellular carcinoma and melanoma $(18,19)$. 
The aim of this study was to investigate the clinical importance of the CYLD gene by analyzing 124 consecutive patients with $\mathrm{HCC}$ who were treated with hepatic resection. Distribution of the CYLD protein expression was also examined using immunohistochemistry.

\section{Materials and methods}

Clinical tissue samples. Between 2005 and 2010, 124 patients (100 men and 24 women) with HCC were registered at the Department of Gastroenterological Surgery, of the Kumamoto University Hospital (Kumamoto, Japan). Specimens of primary HCC and adjacent normal liver tissues were obtained from the patients after written informed consent was obtained. This study was approved by the Human Ethics Review Committee of the Graduate School of Medical Sciences, Kumamoto University (Kumamoto, Japan).

RNA extraction and quantitative reverse transcription-polymerase chain reaction ( $q R T-P C R)$. Total RNA was obtained from the frozen tissue samples and cell lines using a mirVana ${ }^{\mathrm{TM}}$ miRNA Isolation kit (Ambion, Austin, TX, USA) according to the manufacturer's instructions. Reverse transcription was performed with $1.0 \mu \mathrm{g}$ of total RNA as previously described (20). qRT-PCR was performed on a LightCycler 480 II (Roche Diagnostics, Tokyo, Japan) using 2X PCR Master mix (Roche Diagnostics) and Universal ProbeLibrary (Roche Diagnostics). Primers were designed using the Roche website and the Universal ProbeLibrary according to the manufacturer's instructions. The primers used were: CYLD, F: 5'-TCTATGG GGTAATCCGTTGG-3' and R: 5'-CAGCCTGCACACTCAT CTTC-3', and universal probe no. 83; and hypoxanthine phosphoribosyltransferase (HPRT), F: 5'-TGACCTTGATTTA TTTTGCATACC-3' and R: 5'-CGA GCAAGACGTTCAGT CCT-3', and universal probe no. 73. HPRT, 18 S ribosomal RNA (rRNA) and glyceraldehyde 3-phosphate dehydrogenase $(G A P D H)$ were examined as the internal controls (21). HPRT was proved to be the most suitable reference gene. For amplification, an initial denaturation at $95^{\circ} \mathrm{C}$ for $10 \mathrm{~min}$ was followed by 45 cycles for $15 \mathrm{sec}$ at $95^{\circ} \mathrm{C}$, annealing $15 \mathrm{sec}$ at $60^{\circ} \mathrm{C}$, and extension $13 \mathrm{sec}$ at $72^{\circ} \mathrm{C}$. The experiments were performed twice to confirm reproducibility.

Immunohistochemistry and evaluation of CYLD. Paraffin-embedded tissue sections were dewaxed with xylene and rehydrated using graded concentrations of ethanol. The samples were then stained for CYLD using our previously described technique (22). Endogenous peroxidase activity was blocked using $3 \%$ hydrogen peroxide. The sections were incubated in 200X diluted primary rabbit anti-CYLD antibody (Sigma, Tokyo, Japan) overnight at $4^{\circ} \mathrm{C}$. A subsequent reaction was performed with a biotin-free horseradish peroxidase enzyme-labeled polymer of the EnVision Plus detection system (Dako Co., Tokyo, Japan). A positive reaction was visualized with a 3,3'-diaminobenzidine (DAB) solution, followed by counterstaining with Mayer's hematoxylin. Each immunohistochemical marker was independently evaluated by two blinded investigators. CYLD expression status in HCC cells was quantified as a percentage of the total number of stained cells detected in $\geq 5$ random high-power fields (magnification, $\mathrm{x} 400$ ) in each section. The positivity of staining cells with $10 \%$ was determined as the cut-off value.

Statistical analysis. Statistical analysis was performed using the JMP ${ }^{\circledR} 8.0$ software (SAS Institute., Cary, NC, USA). Values were presented as the mean \pm standard deviation (SD). Differences between groups were calculated using the Wilcoxon test. $\mathrm{P}<0.05$ was considered to indicate a statistically significant difference.

\section{Results}

Expression of CYLD in clinical tissue specimens and their clinicopathological characteristics. We performed qRT-PCR analysis in the primary HCC specimens. CYLD expression was quantified by caluculating the ratio of CYLD to HPRT1 signal. $C Y L D$ expression was detected in the tumor and non-tumor tissues. CYLD expression of tumor tissue was not markedly different compared to that of non-tumor liver tissue. For the clinicopathological evaluation, patients were allocated into two groups based on the median value of tumor-to-non-tumor $(\mathrm{T} / \mathrm{N})$ ratio of $C Y L D$ expression. Patients with a $\mathrm{T} / \mathrm{N}$ ratio larger than the median $\mathrm{T} / \mathrm{N}$ ratio of $C Y L D$ expression were allocated to the high expression group, while the remaining patients comprised the low expression group. Clinicopathological characteristics associated with the CYLD expression status of the 124 patients are summarized in Table I. CYLD expression was only correlated with the serum $\alpha$-fetoprotein (AFP) value $(\mathrm{P}=0.0093)$.

Correlation between CYLD expression and prognosis. The correlation between each clinicopathological characteristic and prognosis was analyzed by univariate analyses (Table II). The data indicated that poor prognosis in HCC patients correlated with tumor a diameter of $>35.5 \mathrm{~mm}(\mathrm{P}<0.0001)$, multiple tumors $(\mathrm{P}=0.0048)$, positive vascular invasion $(\mathrm{P}=0.0021)$, the protein induced by vitamin $\mathrm{K}$ absence or antagonist (PIVKA)-II $>108$ $(\mathrm{P}=0.0278)$, and low $C Y L D$ expression $(\mathrm{P}=0.0406)$ (Fig. 1A). In the multivariate analysis, $C Y L D$ expression was not an independent factor for predicting poor prognosis (data not shown). Although $C Y L D$ expression was not significantly correlated with disease-free survival ( $\mathrm{P}=0.1021)$ (Fig. 1B), the low $C Y L D$ expression group had more patients with early recurrence within 2 years (30/37 patients) compared to the high CYLD expression group (17/31 patients; $\mathrm{P}=0.016)$.

Expression of CYLD protein. Among $70 \mathrm{HCC}$ cases, 53 (75.7\%) were positive for CYLD expression. CYLD expression was heterogeneously distributed in the tumor tissue and downregulated in tumor cells. In Fig. 2A, a representative case of HCC shows that a number of tumor cells (T1) with a high CYLD expression are well-differentiated and that they demonstrate a trabecular pattern. Conversely, other tumor cells (T2) with low CYLD expression lost their cell polarity and demonstrated dense chromatin in the nucleus. Another case of HCC comprising tumor cells with dense chromatin and a small nucleus that lost CYLD expression, despite being surrounded by CYLD-expressing tumor cells with more cytoplasm and only faint chromatin in the nucleus (Fig. 2B). However, CYLD protein expression was not associated with tumor-related 
A

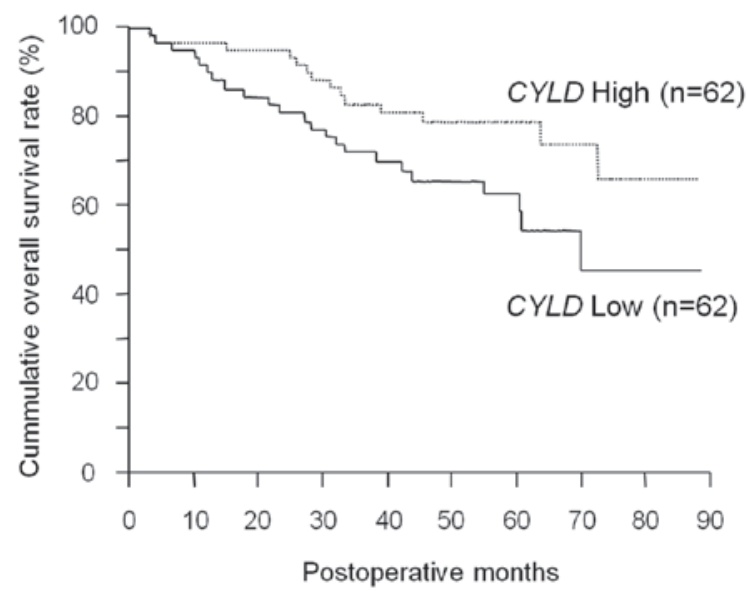

B

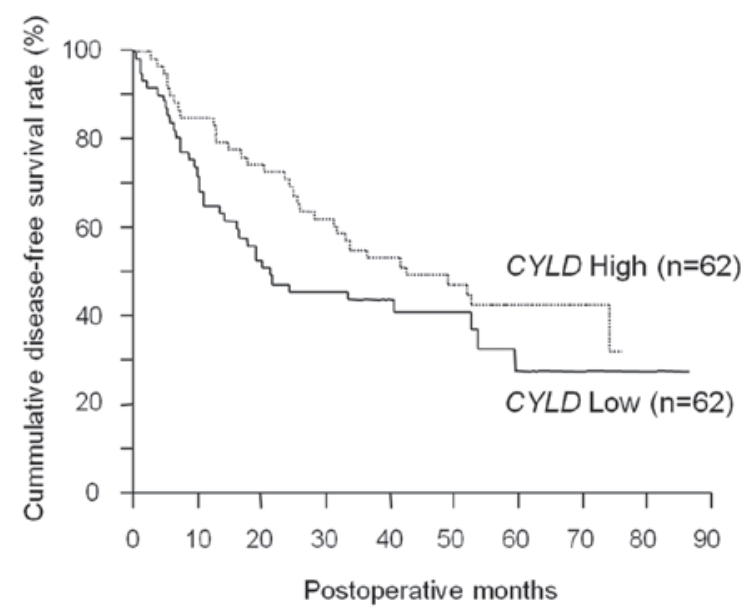

Figure 1. Clinical correlation of $C Y L D$ expression with HPC prognosis qRT-PCR analysis of $C Y L D$ was performed in HCC patients. (A) Overal survival rates of HCC patients based on CYLD-mRNA expression status are shown. The overall survival rate was lower in the high compared to the low CYLD expression group ( $\mathrm{P}=0.0406)$. (B) Disease-free survival rates were lower in the high compared to the low $C Y L D$ expression group $(\mathrm{P}=0.1021)$. CYLD, cylindromatosis gene; qRT-PCR, quantitative reverse transcriptionpolymerase chain reaction; HCC, hepatocellular carcinoma.

factors, such as tumor size, tumor diameter, vascular invasion, tumor differentiation and prognosis (data not shown). To confirm the correlation of CYLD-mRNA expression with protein expression, $C Y L D$-mRNA expression normalized by $H P R T$-mRNA expression in tumor tissue was compared between the high and low-CYLD protein expression groups. This finding showed that the high-CYLD protein expression group demonstrated a markedly higher $C Y L D$-mRNA expression compared to the low-CYLD protein expression group $(\mathrm{P}=0.036)$ (Fig. 2C).

\section{Discussion}

In this study, we showed that reduced CYLD-mRNA expression is associated with a poor prognosis in HCC patients, since the incidence of early recurrence (i.e., within 2 years) was higher in the low compared to the high-CYLD expression group. The pattern of recurrence was similar between the
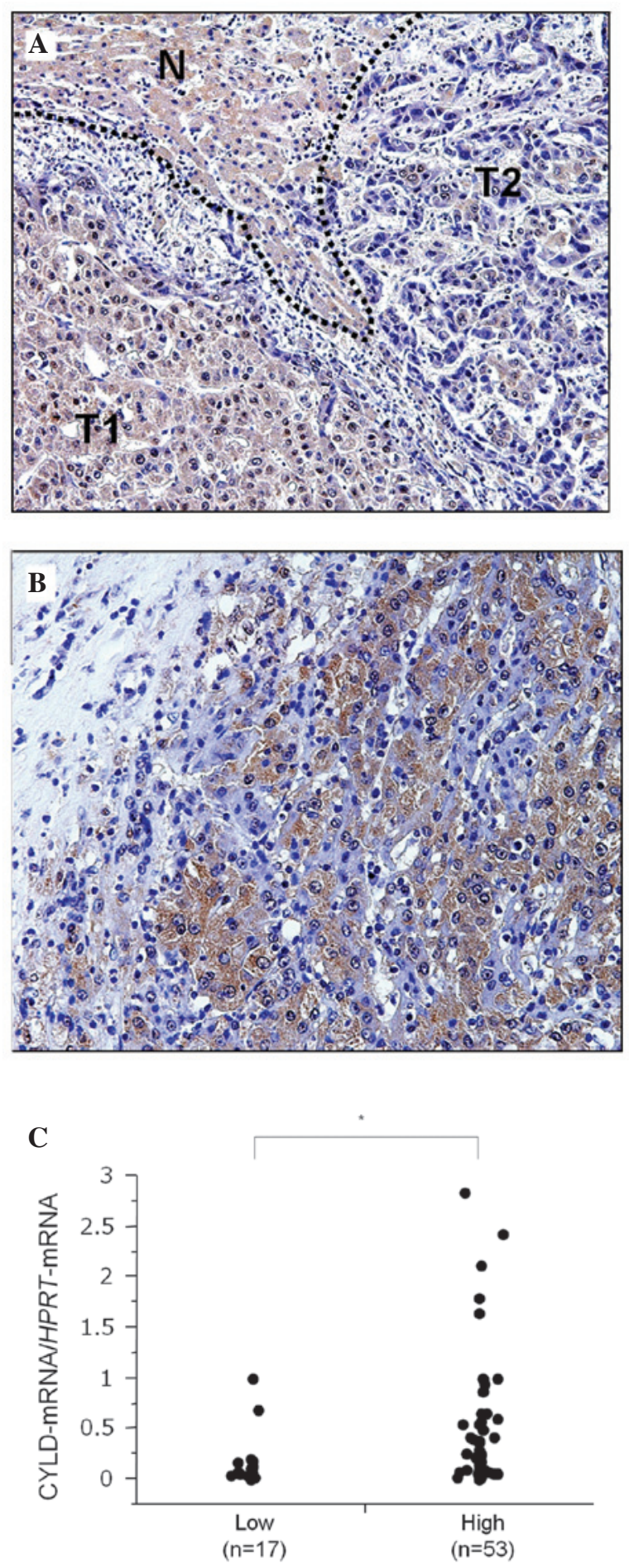

CYLD protein expression

Figure 2. CYLD protein expression in human HCC. (A) Representative CYLD immunohistochemical image of an HCC tumor. Normal hepatocytes (N) and T1 tumor cells demonstrated similar expression levels of CYLD. T2 tumor cells with irregular cell polarity and dense chromatin in the nucleus showed a reduced CYLD expression. The dotted line divides normal hepatocytes and tumor cells. Magnification, x100. (B) Representative CYLD immunohistochemical image of another HCC tumor. Two morphologically distinct types of tumor cells are present that can be distinguished based on the appearance of their nucleus. Cells with high CYLD expression have a faint large nucleus, while others with low CYLD expression have a small dense nucleus. Magnification, x200. (C) The CYLD-mRNA level normalized to $H P R T$-mRNA in the low CYLD protein expression group was markedly lower compared to that of the high-CYLD expression group $(\mathrm{P}=0.036)$. " $\mathrm{P}<0.05$. CYLD, cylindromatosis; HCC, hepatocellular carcinoma; HPRT, hypoxanthine phosphoribosyltransferase. 
Table I. CYLD-mRNA expression and patient clinicopathological characteristics.

CYLD (T/N ratio)

Clinicopathological characteristics

No. of patients

High

Low

P-value

Age $^{\text {a }}$ (years)

$<66$

63

30

33

0.7637

$\geq 66$

61

32

29

Gender

Male

49

51

Female

24

13

11

$\mathrm{AFP}^{\mathrm{b}}(\mathrm{U} / \mathrm{ml})$

$<15.2$

68

$\geq 15.2$

56

PIVKA-II ${ }^{\mathrm{a}}(\mathrm{U} / \mathrm{ml})$

$$
\begin{aligned}
& <108 \\
& \geq 108
\end{aligned}
$$

69

Tumor diameter ${ }^{\mathrm{a}}(\mathrm{mm})$

$<35.5$

62

$\geq 35.5$

62

No. of tumors

Solitary

Multiple

Differentiation

Well/mod

94

30

103

Poor

Positive

$\mathrm{HCV}-\mathrm{Ab}$

Negative

70

54

HBs-Ag

Negative

Positive

Liver cirrhosis ${ }^{\mathrm{d}}$

Negative

Positive
Negative

Positive
41

27

21

35

31

30

31

32

32

30

30

32

43

44

18

0.0093

19

${ }^{\mathrm{a}}$ Cut-off value defined as the median value; ${ }^{\mathrm{b}}$ cut-off value defined as the maximum normal value; ${ }^{\mathrm{c}}$ pathological vascular invasion; ${ }^{\mathrm{d}} \mathrm{clasified}$ as F4 stage in the Inuyama classification (25). CYLD, cylindromatosis; T/N, tumor to non-tumor; AFP, $\alpha$-fetoprotein; PIVKA-II, the protein induced by vitamin $\mathrm{K}$ absence or antagonist-II; well/mod, well/moderately-differentiated hepatocellular carcinoma; poor, poorly-differentiated hepatocellular carcinoma; HCV-Ab, hepatitis C virus; HBs-Ag, hepatitis B virus.

two groups. Since intrahepatic recurrence within 2 years is considered an intrahepatic metastasis from the primary tumor, this outcome suggests that $C Y L D$ is associated with metastatic potential and, thus, a poor prognosis. $C Y L D$-mRNA expression demonstrated no correlation with tumor-related factors with the exception of serum AFP. AFP production has been strongly associated with specific molecular subtypes of HCC, such as hepatoblastoma (23), while a reduced CYLD expression may therefore be associated with a specific molecular phenotype.

A recent in vivo study demonstrated that a liver-specific conditional knockout of CYLD induced apoptosis in hepatocytes via the chronic activation of TGF- $\beta$-activated kinase 1 and c-Jun N-terminal kinase (JNK) in the periportal area. 
Table II. Univariate analysis of clinicopathological characteristics for overall survival of patients.

\begin{tabular}{lccc}
\hline $\begin{array}{l}\text { Clinicopathological } \\
\text { characteristics }\end{array}$ & $\begin{array}{c}\text { No. of } \\
\text { patients }\end{array}$ & $\begin{array}{c}\text { Median } \\
\text { survival } \\
\text { (months) }\end{array}$ & P-value \\
\hline
\end{tabular}

Age $^{\mathrm{a}}$ (years)
$<66$
$\geq 66$

63

36.0

0.4168

Gender

$\begin{array}{lrrr}\text { Male } & 106 & 46.7 & 0.5799 \\ \text { Female } & 24 & 41.3 & \end{array}$

$\mathrm{AFP}^{\mathrm{b}}$

$<15.2$

$\geq 15.2$

68

38.7

0.5008

PIVKA-II ${ }^{\mathrm{a}}$

$<108$
$\geq 108$

42.2

Tumor diameter ${ }^{\mathrm{a}}(\mathrm{mm})$

$\begin{array}{lll}<35.5 & 62 & 45.2 \\ \geq 35.5 & 62 & 33.1\end{array}$

No. of tumors

$\begin{array}{lrr}\text { Solitary } & 94 & 41.2 \\ \text { Multiple } & 30 & 36.6 \\ \text { Differentiation } & & \\ \text { Well/mod } & 103 & 41.7 \\ \text { Poor } & 21 & 37.3\end{array}$

Vascular invasion ${ }^{\mathrm{c}}$

$\begin{array}{llll}\text { Negative } & 66 & 42.7 & 0.0021 \\ \text { Positive } & 56 & 38.1 & \\ \text { HCV-Ab } & & & \\ \text { Negative } & 72 & 42.0 & 0.8255 \\ \text { Positive } & 58 & 44.7 & \\ \text { HBs-Ag } & & & \\ \text { Negative } & 91 & 44.8 & 0.3037 \\ \text { Positive } & 39 & 42.0 & \\ \text { Liver cirrhosis }{ }^{\mathrm{d}} & & & \\ \text { Negative } & 87 & 42.7 & 0.7831 \\ \text { Positive } & 37 & 43.9 & \\ \text { CYLD (T/N ratio) } & & & \\ \text { Low } & 62 & 41.1 & 0.0406 \\ \text { High } & 62 & 37.0 & \\ \end{array}$

${ }^{a}$ Cut-off value defined as the median value; ${ }^{b}$ cut-off value defined as the maximum normal value; ${ }^{c}$ pathological vascular invasion; ${ }^{\mathrm{d}} \mathrm{classi}$ fied as F4 stage in the Inuyama classification (25). AFP, $\alpha$-fetoprotein; PIVKA-II, the protein induced by vitamin $\mathrm{K}$ absence or antagonist-II; well/mod, well/moderately-differentiated hepatocellular carcinoma; poor, poorly-differentiated hepatocellular carcinoma; HCV-Ab, hepatitis $\mathrm{C}$ virus; HBs- $\mathrm{Ag}$, hepatitis B virus; CYLD, cylindromatosis; $\mathrm{T} / \mathrm{N}$, tumor to non-tumor.
As a result, this promoted progressive fibrosis and inflammation, resulting in cancer development (24). Although CYLD expression was expected to be potentially associated with certain types of carcinogenesis from viral hepatitis or liver cirrhosis due to chronic inflammation, no correlation was observed between CYLD expression and non-tumor liver tissue. A previous in vitro study demonstrated that HCC cells transfected with the CYLD gene showed an increased $\mathrm{NF}-\kappa \mathrm{B}$ reporter activity (18). The present study supports the clinical and oncological importance of CYLD in HCC progression.

A limited number of clinical studies have investigated the protein expression and distribution of CYLD in solid types of cancer such as HCC. Notably, in this study, immunohistochemical analysis showed that CYLD expression was distributed according to tumor cell morphology within the same tumor, and tumor cells that lost their cell polarity tended to lose CYLD expression. The mechanism underlying staining pattern remains unclear, and further investigation is required to better understand the role of CYLD in dysplastic cell morphology and chromatin structure.

In conclusion, the present study suggests that CYLD is associated with tumor development in HCC patients. This is a preliminary study and, as a result, the functional aspect of CYLD in HCC patients needs to be further investigated. However, the present study is considered to be useful in investigating whether CYLD may be a future molecular target in HCC patients.

\section{References}

1. Siegel R, Naishadham D and Jemal A: Cancer statistics. CA Cancer J Clin 62: 10-29, 2012.

2. Carr BI: Hepatocellular carcinoma: current management and future trends. Gastroenterology 127: S218-S224, 2004.

3. Bignell GR, Warren W and Seal S, et al: Identification of the familial cylindromatosis tumour-suppressor gene. Nat Genet 25: 160-165, 2000.

4. Jin W, Chang M, Paul EM, et al: Deubiquitinating enzyme CYLD negatively regulates RANK signaling and osteoclastogenesis in mice. J Clin Invest 118: 1858-1866, 2008.

5. Reiley WW, Jin W, Lee AJ, et al: Deubiquitinating enzyme CYLD negatively regulates the ubiquitin-dependent kinase Tak1 and prevents abnormal T cell responses. J Exp Med 204: 1475-1485, 2007.

6. Wright A, Reiley WW, Chang M, et al: Regulation of early wave of germ cell apoptosis and spermatogenesis by deubiquitinating enzyme CYLD. Dev Cell 13: 705-716, 2007.

7. Zhang J, Stirling B, Temmerman ST, et al: Impaired regulation of NF-kappaB and increased susceptibility to colitis-associated tumorigenesis in CYLD-deficient mice. J Clin Invest 116: 3042-3049, 2006.

8. Brummelkamp TR, Nijman SM, Dirac AM and Bernards R: Loss of the cylindromatosis tumour suppressor inhibits apoptosis by activating NF-kappaB. Nature 424: 797-801, 2003.

9. Kovalenko A, Chable-Bessia C, Cantarella G, et al: The tumour suppressor CYLD negatively regulates NF-kappaB signalling by deubiquitination. Nature 424: 801-805, 2003.

10. Trompouki E, Tsagaratou A, Kosmidis SK, et al: Truncation of the catalytic domain of the cylindromatosis tumor suppressor impairs lung maturation. Neoplasia 11: 469-476, 2009.

11. Lim JH, Jono H, Komatsu K, et al: CYLD negatively regulates transforming growth factor- $\beta$-signalling via deubiquitinating Akt. Nat Commun 3: 771, 2012.

12. Jenner MW, Leone PE, Walker BA, et al: Gene mapping and expression analysis of $16 \mathrm{q}$ loss of heterozygosity identifies WWOX and CYLD as being important in determining clinical outcome in multiple myeloma. Blood 110: 3291-3300, 2007.

13. Annunziata CM, Davis RE, Demchenko Y, et al: Frequent engagement of the classical and alternative NF-kappaB pathways by diverse genetic abnormalities in multiple myeloma. Cancer Cell 12: 115-130, 2007. 
14. Keats JJ, Fonseca R, Chesi M, et al: Promiscuous mutations activate the noncanonical NF-kappaB pathway in multiple myeloma. Cancer Cell 12: 131-144, 2007.

15. Hashimoto K, Mori N, Tamesa T, et al: Analysis of DNA copy number aberrations in hepatitis $\mathrm{C}$ virus-associated hepatocellular carcinomas by conventional CGH and array CGH. Mod Pathol 17: 617-622, 2004.

16. Hirai Y, Kawamata Y, Takeshima N, et al: Conventional and array-based comparative genomic hybridization analyses of novel cell lines harboring HPV18 from glassy cell carcinoma of the uterine cervix. Int J Oncol 24: 977-986, 2004.

17. Ströbel P, Zettl A, Ren Z, et al: Spiradenocylindroma of the kidney: clinical and genetic findings suggesting a role of somatic mutation of the CYLD1 gene in the oncogenesis of an unusual renal neoplasm. Am J Surg Pathol 26: 119-124, 2002.

18. Hellerbrand C, Bumes E, Bataille F, et al: Reduced expression of CYLD in human colon and hepatocellular carcinomas. Carcinogenesis 28: 21-27, 2007.

19. Massoumi R, Kuphal S, Hellerbrand C, et al: Down-regulation of CYLD expression by Snail promotes tumor progression in malignant melanoma. J Exp Med 206: 221-232, 2009.
20. Okabe H, Beppu T, Ueda M, et al: Identification of CXCL5/ENA-78 as a factor involved in the interaction between cholangiocarcinoma cells and cancer-associated fibroblasts. Int J Cancer: Feb 15, 2012 (Epub ahead of print).

21. Fu LY, Jia HL, Dong QZ, et al: Suitable reference genes for real-time PCR in human HBV-related hepatocellular carcinoma with different clinical prognoses. BMC Cancer 9: 49, 2009.

22. Okabe H, Beppu T, Hayashi H, et al: Hepatic stellate cells may relate to progression of intrahepatic cholangiocarcinoma. Ann Surg Oncol 16: 2555-2564, 2009.

23. Lee JS and Thorgeirsson SS: Functional and genomic implications of global gene expression profiles in cell lines from human hepatocellular cancer. Hepatology 35: 1134-1143, 2002.

24. Nikolaou K, Tsagaratou A, Eftychi C, et al: Inactivation of the deubiquitinase CYLD in hepatocytes causes apoptosis, inflammation, fibrosis, and cancer. Cancer Cell 21: 738-750, 2012. 